\title{
Diabetes and Hypertension: Is There a Common Metabolic Pathway?
}

\author{
Bernard M. Y. Cheung • Chao Li
}

Published online: 27 January 2012

(C) The Author(s) 2012. This article is published with open access at Springerlink.com

\begin{abstract}
Diabetes and hypertension frequently occur together. There is substantial overlap between diabetes and hypertension in etiology and disease mechanisms. Obesity, inflammation, oxidative stress, and insulin resistance are thought to be the common pathways. Recent advances in the understanding of these pathways have provided new insights and perspectives. Physical activity plays an important protective role in the two diseases. Knowing the common causes and disease mechanisms allows a more effective and proactive approach in their prevention and treatment.
\end{abstract}

Keywords Diabetes $\cdot$ Hypertension · Obesity $\cdot$ Metabolic syndrome $\cdot$ Metabolic pathway $\cdot$ Insulin resistance

\section{Introduction}

Hypertension and diabetes are two of the leading risk factors for atherosclerosis and its complications, including heart attacks and strokes. There is substantial overlap between diabetes and hypertension, reflecting substantial overlap in their etiology and disease mechanisms. In the Hong Kong Cardiovascular Risk Factor Prevalence Study, only $42 \%$ of people with diabetes had normal blood pressure and only

B. M. Y. Cheung $\cdot$ C. Li

Department of Medicine, University of Hong Kong,

Pokfulam, Hong Kong

C. $\mathrm{Li}$

e-mail: dcli@hku.hk

B. M. Y. Cheung $(\bowtie)$

Department of Medicine, Queen Mary Hospital,

102 Pokfulam Road,

Hong Kong, China

e-mail: mycheung@hku.hk
$56 \%$ of people with hypertension had normal glucose tolerance [1•]. In the US population, hypertension occurs in approximately $30 \%$ of patients with type 1 diabetes and in $50 \%$ to $80 \%$ of patients with type 2 diabetes [2]. A prospective cohort study in the United States reported that type 2 diabetes mellitus was almost 2.5 times as likely to develop in subjects with hypertension as in subjects with normal blood pressure [3]. In reality, diabetes and hypertension are found in the same individual more often than would occur by chance, whereas the overlap between dysglycemia and raised blood pressure is even more substantial than that between diabetes and hypertension [4]. This suggests either shared genetic or environmental factors in the etiology [1•].

\section{Etiology}

\section{Genetics}

Genome scans involving thousands of subjects and controls have revealed a large number of genes with small effects, as opposed to a small number of genes with large effects anticipated originally $[5,6]$. Genetic variants in the gene encoding angiotensinogen, adrenomedullin, apolipoprotein, and $\alpha$-adducin have been reported to be associated with common conditions such as diabetes, hypertension, dysglycemia, or metabolic syndrome [7-10].

In Hong Kong studies of single nucleotide polymorphisms (SNPs), SNPs that predict the development of diabetes were found also to predict the development of hypertension [11-14]. In genome scans in Hong Kong Chinese individuals, the region associated with diabetes was also associated with the metabolic syndrome, which includes hypertension as a component $[15,16]$. A recent study at Columbia University on somatic gene conversion 
and deletion suggested that multitudes of common SNPs are involved [17•].

Besides the genetic aspect, another very important aspect for the onset of diabetes and hypertension is environmental. Environmental factors include the period in utero and lifestyle factors such as diet and physical activity. Gestational diabetes, fetal malnutrition, and high birth weight are three factors that may predispose the fetus to cardiometabolic syndrome in adulthood [18, 19•, 20]. High intake of sodium, alcohol, and unsaturated fat, smoking, lack of physical activity, and mental stress are examples of an unhealthy lifestyle.

It is now realized that insulin resistance, which predicts type 2 diabetes, also has a role in the development of hypertension [21]. Indeed, hypertension and diabetes substantially share common pathways such as obesity, inflammation, oxidative stress, insulin resistance, and mental stress.

\section{Obesity}

Obesity, a global health problem, has been identified as the most important risk factor for hypertension and diabetes [22]. Obese persons have a significantly higher risk of hypertension and type 2 diabetes [23•]. Studies of obesity in Western countries where there is a high prevalence have led to a greater understanding of the phenomenon of risk factor clustering and of the pathophysiologic links among hypertension, obesity, diabetes. Obesity is generally considered as the combined result of dysfunction of feeding center in the brain, imbalance in energy intake and expenditure, and genetic variations. Obesity is largely determined by genes; approximately $50 \%$ to $90 \%$ of the variation in weight is the result of genetic predisposition according to twin studies [24, 25]

The obese (ob) gene that was discovered in 1950 was the first gene identified to be related to the onset of obesity [26]. From then on, researchers have sought to identify the genetic factors of obesity in addition to studying metabolic physiology. Genome-wide association studies have revealed a number of genes influencing the susceptibility to obesity [27-29]. The FTO gene, promoting obesity and overeating, was one of the key obesity susceptibility genes. Together with the GNDPA 2 gene, they predict persistent central obesity in the Chinese population [10]. Other likely diabetes-related genes include BCDIN3D/FAIM2, SH2B1, and KCTD15 [29-32] as well as $C R T C 3$, which has been shown to slow down the speed of fat oxidation [33].

It is not surprising to find that diabetes and obesity share some common susceptibility genes. As obesity is a common factor in the etiology of hypertension and diabetes [1•], we would expect that hypertension, diabetes, and obesity not only share common pathophysiologic pathways but also common susceptibility genes.
Inflammation and Oxidative Stress

A low-grade inflammatory process occurs in both diabetes and hypertension [34-38]. Even chronic periodontitis is a latent factor in the development of diabetes, hypertension, cardiovascular diseases, and the metabolic syndrome [39-45]. In some ways, diabetes and hypertension could be considered as chronic inflammatory diseases.

Inflammatory markers (eg, C-reactive protein (CRP)) are increased in patients with diabetes, hypertension, and the metabolic syndrome, and also predict the development of these diseases [46-48]. The local renin-angiotensinaldosterone system (RAAS) plays a very important role in vascular pathophysiology. Angiotensin-converting enzyme (ACE) is expressed in the shoulder of coronary artery plaques. Angiotensin II (Ang II) is to a large degree responsible for triggering vascular inflammation and inducing oxidative stress [49]. It stimulates NADH/NADPH oxidase, and activates Rho/Rho kinase, protein kinase $\mathrm{C}$ (PKC), and mitogen-activated protein kinase (MAPK) [50-53]. Also, Ang II down-regulates proinflammatory transcription factors such as nuclear factor- $\mathrm{kB}(\mathrm{NF}-\mathrm{kB})$, resulting in the generation and secretion of reactive oxygen species (ROS), inflammatory cytokines (eg, interleukin-6 [IL-6]), chemokines, and adhesion molecules $[54,55]$. These actions lead to endothelial dysfunction and vascular injury.

Gene regulatory network analysis has revealed oxidative stress as a key underlying molecular mechanism in diabetes and hypertension. The oxidative stress-mediated regulation cascade is the common mechanistic link among the pathogenesis of diabetes, hypertension, and other related inflammatory diseases [56].

Peroxisome proliferator-activated receptor (PPAR) activators lower blood pressure, induce favorable effects on the heart, and ameliorate endothelial dysfunction through antioxidant, anti-inflammatory, antiproliferative, antihypertrophic, and antifibrotic effects [57]. Ang II down-regulates the mRNA and protein of PPAR- $\alpha$ and PPAR- $\gamma$, resulting in the reduction of PPAR anti-inflammatory capacity and activation of inflammation. PPAR- $\alpha$ and PPAR- $\gamma$ activators have been demonstrated to exert cardiovascular protective effects independent of their metabolic actions [58]. However, recent studies with dual PPAR activators have cast doubts on their clinical efficacy in cardiovascular prevention compared with the original PPAR activators currently marketed $[59,60]$.

Traditional pharmacologic approaches such as statins, ACE inhibitors, and Ang II receptor blockers (ARBs), which reduce cardiovascular events in randomized clinical trials, also reduce vascular inflammation in patients with diabetes and hypertension [61-63]. Optimization of lifestyle (eg, weight loss, exercise, and Mediterranean-style diet) also has the effect of reducing vascular inflammation [64, 65•]. 


\section{Insulin Resistance}

Insulin is a pleiotropic hormone that plays a pivotal role in the development of hypertension, diabetes, and the metabolic syndrome. The main metabolic actions of insulin are to stimulate glucose uptake in skeletal muscle and heart and to suppress the production of glucose and very low-density lipoprotein (VLDL) in the liver [66]. Under fasting conditions, insulin secretion is suppressed, leading to increased glucose synthesis in the liver and kidneys (gluconeogenesis) and increased conversion of glycogen to glucose in the liver (glycogenolysis) [67]. After a meal, insulin is released from pancreatic $\beta$-cells and inhibits gluconeogenesis and glycogenolysis [67]. Insulin stimulates the sympathetic nervous system (SNS) to increase cardiac output and the delivery and utilization of glucose in the peripheral tissues [68]. Other metabolic effects of insulin include inhibition of glucose release from the liver, inhibition of the release of free fatty acids (FFAs) from adipose tissue, and stimulation of the process by which amino acids are incorporated into protein [67].

Insulin resistance, a condition in which defects in the action of insulin are such that normal levels of insulin do not trigger the signal for glucose absorption, denotes an impaired response to insulin in skeletal muscle, liver, adipose, and cardiovascular tissue $[67,68]$. Insulin resistance arises due to various genetic, acquired, and environmental factors, including obesity [69]. Increased RAAS activities may also cause insulin resistance via the stimulation of Ang II type 1 receptors, which trigger increased production of reactive oxygen species (ROS) in adipocytes, skeletal muscle, and cardiovascular tissue of obese individuals [70, 71]. FFAs are believed to induce insulin resistance and increase the level of oxidative stress [70, 72, 73], resulting in endothelial dysfunction and atherogenesis $[69,70]$.

Insulin resistance is associated with impaired insulin signaling, impaired fibrinolysis, and inflammation. Emerging evidence suggests that insulin resistance may result from abnormalities in key molecules of the insulin-signalling pathways, including overexpression of phosphatases and downregulation and/or activation of protein kinase cascades [74], leading to abnormalities in the expression and action of various cytokines, growth factors, and peptides, and overproduction of VLDL [75]. Insulin resistance may also result in impaired fibrinolysis, which is characterized by hypercoagulability and elevation of fibrinogen and plasminogen activator inhibitor (PAI)-1 [76, 77]. PAI-1 activity is elevated in a wide variety of insulin resistance patients. Even in patients with normal glucose tolerance, elevated levels of fasting insulin are associated with impaired fibrinolysis [76]. Therefore, insulin resistance is a prothrombotic state characterized by an elevation of PAI-1 and fibrinogen levels, leading to increased risk of cardiovascular events [75, 77].
Insulin resistance may be a result of an overproduction of proinflammatory cytokines (eg, IL-6, tumour necrosis factor (TNF), and CRP) and a relative deficiency of antiinflammatory cytokines (eg, adiponectin) produced from adipose tissues due to obesity [78].

Insulin-mediated glucose uptake by muscle varies more than sixfold in apparently healthy individuals [79], with approximately half of the variability in insulin action being genetically determined and the other half resulting from differences in the degree of adiposity and physical fitness $[80,81]$. Most patients with type 2 diabetes are insulin resistant, and about half of those with essential hypertension are insulin resistant [82]. Therefore, insulin resistance is an important common link between diabetes and hypertension.

\section{Mental Stress and Sympathetic Nervous System}

Stressors are intrinsic or extrinsic stimuli leading to disturbances in physiology and psychology, and may threaten health. Compared with physical stressors, modern stressors arising from psychological threat (eg, work stress, domestic violence, and natural disasters) are more sustained. Chronic mental stress, resulting from the modern lifestyle, is frequently associated with physiologic and psychological disturbances, and may indirectly lead to diabetes and hypertension [83-87].

Although epidemiologic investigations have demonstrated that mental stress is associated with hypertension, cardiovascular disease, obesity, and the metabolic syndrome (which includes diabetes as a component) [88-92], the effect of mental stress on the whole body is not completely understood. Animal experiments taught us that the mechanisms include renal sympathetic nerve activity (RSNA) [93, 94] and blood pressure control in which baroreflex function [95-97] is involved.

In the human body, stimulation of the sympathetic nervous system (SNS), caused by chronic stress, elevates pulse rate and cardiac minute output and also activates the RAAS, which is another important pressor mechanism [86]. Increased activity of the SNS also plays a part in the development of impaired glucose [87] and lipid metabolism [83, 98]. Studying the SNS and RAAS allows us to understand their roles in the etiology and treatment of hypertension, metabolic syndrome, and diabetes [84].

There is also a link between mental stress and obesity in patients with diabetes and hypertension. A high prevalence of hypertension in obese subjects has been related to psychosocial factors, including chronic stress [99-101]. The hypothalamicpituitary-adrenal axis was suggested as a key mechanism linking obesity, hypertension, and chronic stress [101, 102]. Therefore, people should reduce stress to escape from the vicious cycle of mental stress, obesity, diabetes, and hypertension. 
Physical Activity

In the Da Qing Impaired Glucose Tolerance and Diabetes Study, incident diabetes decreased by $46 \%$ in the exercise group [103]. In the nonrandomized Malmö Feasibility Study in 260 middle-aged men with impaired glucose tolerance, the incidence of diabetes was $50 \%$ lower in the intervention group after 5 years [104]. In the Finnish Diabetes Prevention Study, subjects with a change in moderate-to-vigorous leisure-time physical activity (LTPA) in the highest tertile were $49 \%$ to $65 \%$ less likely to develop diabetes than those in the lowest tertile [105]. In the Coronary Artery Risk Development in Young Adults study (CARDIA) with over 15 years of follow-up, there was a significant $17 \%$ reduction of risk of incident hypertension for every 300 -exercise unit increment in average physical activity [106]. In the Atherosclerosis Risk in Communities (ARIC) study, the highest quartile of leisure activity (primarily cycling and walking) had a 34\% lower odds of developing hypertension over 6 years compared to the least active [107]. Thus, physical activity reduces the risk of developing diabetes and hypertension. The mechanism involves changes in body weight and glucose tolerance, as well as other factors [107].

The effect of obesity susceptibility genes on the onset of obesity is influenced by physical activity in the individual. The genotypic effect of FTO is more pronounced in inactive than active individuals [108•]. The former are more likely to carry risk alleles such as rs9939609 [109]. Nevertheless, individuals meeting the daily physical activity recommendations may overcome the effect of FTO genotype on obesity-related diseases such as diabetes, hypertension, and the metabolic syndrome [110-112].

The potential benefits of physical activity in the prevention and treatment of diabetes and hypertension are well recognized but regular physical activity is difficult and sometimes impossible to carry out in real life. Public health efforts should nevertheless still aim to raise public awareness and facilitate regular physical activity to prevent against diabetes, hypertension, and other related diseases.

\section{Conclusions}

Diabetes and hypertension share common pathways such as SNS, RAAS, oxidative stress, adipokines, insulin resistance, and PPARs (Fig. 1). These pathways interact and influence each other and may even cause a vicious cycle. Hypertension and diabetes are both end results of the metabolic syndrome. They may, therefore, develop one after the other in the same individual. Central obesity is the cause of the metabolic syndrome. Only orlistat is currently available for the long-term treatment of obesity [114]. Therefore, optimization of lifestyle

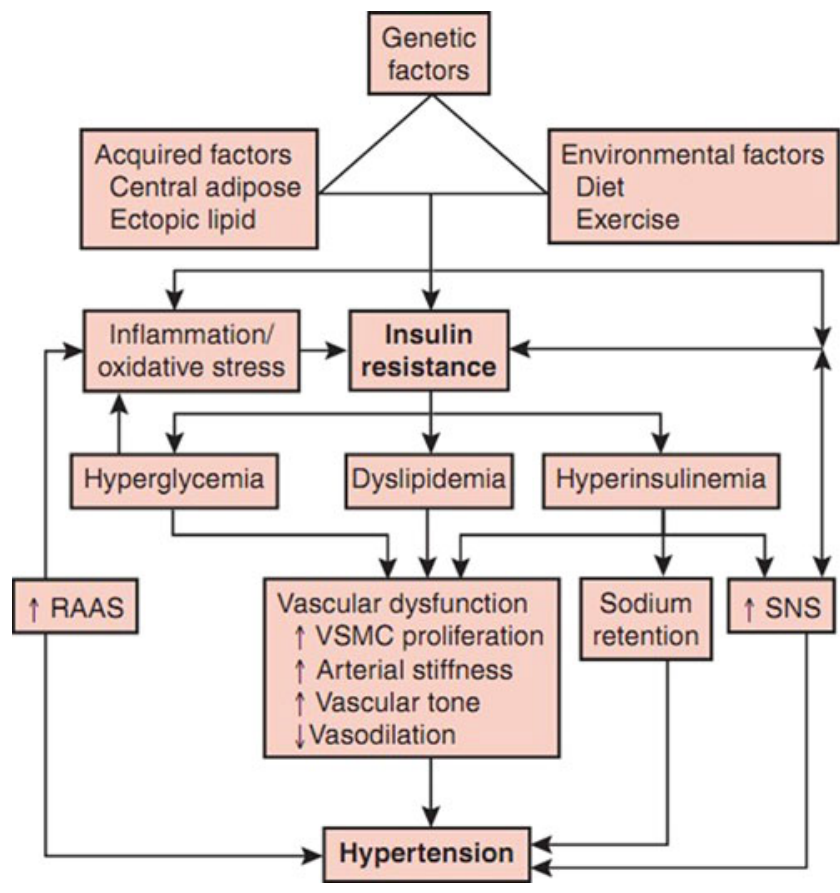

Fig. 1 Summary of putative pathophysiologic mechanisms in the development of hypertension in diabetes mellitus. RAAS - renin-angiotensin-aldosterone system; SNS - sympathetic nervous system; VSMC - vascular smooth muscle cell. (From Mugo MN, Stump CS, Rao PG, Sowers JR. Chapter 34: Hypertension and Diabetes Mellitus. Hypertension: A Companion to Braunwald's Heart Disease. Copyright Elsevier, 2007 [113])

remains the cornerstone in the prevention and treatment of diabetes and hypertension.

Acknowledgements BMY Cheung received support from the Faculty Research Fund, Li Ka Shing Faculty of Medicine, University of Hong Kong.

Disclosure No conflicts of interest relevant to this article were reported.

Open Access This article is distributed under the terms of the Creative Commons Attribution Noncommercial License which permits any noncommercial use, distribution, and reproduction in any medium, provided the original author(s) and source are credited.

\section{References}

Papers of particular interest, published recently, have been highlighted as:

- Of importance

1. Cheung BM. The hypertension-diabetes continuum. J Cardiovasc Pharmacol. 2010; 55: 333-9. This is a brief review of the overlap between hypertension and type 2 diabetes that proposes there is a spectrum ranging from hypertension without dysglycemia to type 2 diabetes without elevated blood pressure. 
2. Landsberg L, Molitch M. Diabetes and hypertension: pathogenesis, prevention and treatment. Clin Exp Hypertens. 2004;26:621-8.

3. Gress TW, Nieto FJ, Shahar E, et al. Hypertension and antihypertensive therapy as risk factors for type 2 diabetes mellitus. Atherosclerosis Risk in Communities Study. N Engl J Med. 2000; 342:905-12.

4. Cheung BM, Wat NM, Tso AW, et al. Association between raised blood pressure and dysglycemia in Hong Kong Chinese. Diabetes Care. 2008;31:1889-91.

5. Zeggini E, Scott LJ, Saxena R, et al. Meta-analysis of genomewide association data and large-scale replication identifies additional susceptibility loci for type 2 diabetes. Nat Genet. 2008; 40:638-45.

6. Sober S, Org E, Kepp K, et al. Targeting 160 candidate genes for blood pressure regulation with a genome-wide genotyping array. PLoS One. 2009;4:e6034.

7. Ong KL, Tso AW, Leung RY, et al. A genetic variant in the gene encoding adrenomedullin predicts the development of dysglycemia over 6.4 years in Chinese. Clin Chim Acta. 2011;412:353-7.

8. Ong KL, Jiang CQ, Liu B, et al. Association of a genetic variant in the apolipoprotein A5 gene with the metabolic syndrome in Chinese. Clin Endocrinol (Oxf). 2011;74:206-13.

9. Cheung CY, Tso AW, Cheung BM, et al. Genetic variants associated with persistent central obesity and the metabolic syndrome in a 12-year longitudinal study. Eur J Endocrinol. 2011;164:3818 .

10. Ong KL, Li M, Tso AW, et al. Association of genetic variants in the adiponectin gene with adiponectin level and hypertension in Hong Kong Chinese. Eur J Endocrinol. 2010;163:251-7.

11. Ong KL, Leung RY, Wong LY, et al. Association of a polymorphism in the lipin 1 gene with systolic blood pressure in men. Am J Hypertens. 2008;21:539-45.

12. Ong KL, Wong LY, Man YB, et al. Haplotypes in the urotensin II gene and urotensin II receptor gene are associated with insulin resistance and impaired glucose tolerance. Peptides. 2006;27: 1659-67.

13. Chow WS, Cheung BM, Tso AW, et al. Hypoadiponectinemia as a predictor for the development of hypertension: a 5-year prospective study. Hypertension. 2007;49:1455-61.

14. Tso AW, Sham PC, Wat NM, et al. Polymorphisms of the gene encoding adiponectin and glycaemic outcome of Chinese subjects with impaired glucose tolerance: a 5-year follow-up study. Diabetologia. 2006;49:1806-15.

15. Ng MC, So WY, Lam VK, et al. Genome-wide scan for metabolic syndrome and related quantitative traits in Hong Kong Chinese and confirmation of a susceptibility locus on chromosome 1q21q25. Diabetes. 2004;53:2676-83.

16. Ng MC, So WY, Cox NJ, et al. Genome-wide scan for type 2 diabetes loci in Hong Kong Chinese and confirmation of a susceptibility locus on chromosome 1q21-q25. Diabetes. 2004;53:1609-13.

17. - Ross KA. Evidence for somatic gene conversion and deletion in bipolar disorder, Crohn's disease, coronary artery disease, hypertension, rheumatoid arthritis, type-1 diabetes, and type- 2 diabetes. BMC Med. 2011; 9: 12. This article showed that somatic gene conversion could be a significant causative factor in seven diseases, including hypertension, type 1 diabetes, and type 2 diabetes. There are some common SNPs identified in some of the seven diseases.

18. Moore TR. Fetal exposure to gestational diabetes contributes to subsequent adult metabolic syndrome. Am J Obstet Gynecol. 2010;202:643-9.

19. - Xita N, Tsatsoulis A. Fetal origins of the metabolic syndrome. Ann N Y Acad Sci. 2010; 1205: 148-55. This article argued that consequences of fetal adaptive responses might be evident later in life rather than at birth. Risk factors in pregnancy might predispose the fetus to hypertension, diabetes, or the metabolic syndrome in adulthood.

20. Guerrero-Romero F, Aradillas-Garcia C, Simental-Mendia LE, et al. Birth weight, family history of diabetes, and metabolic syndrome in children and adolescents. J Pediatr. 2010;156:719-23, $723 \mathrm{e} 1$.

21. Sowers JR. Insulin resistance and hypertension. Am J Physiol Heart Circ Physiol. 2004;286:H1597-1602.

22. Davy KP, Hall JE. Obesity and hypertension: two epidemics or one? Am J Physiol Regul Integr Comp Physiol. 2004;286:R803813.

23. • He YH, Jiang GX, Yang Y, et al. Obesity and its associations with hypertension and type 2 diabetes among Chinese adults age 40 years and over. Nutrition. 2009; 25: 1143-9. This was a crosssectional study of over 5000 people in the community in Shanghai showing that obesity was associated with a higher risk of both hypertension and type 2 diabetes.

24. Loos RJ, Bouchard C. Obesity-is it a genetic disorder? J Intern Med. 2003;254:401-25.

25. Maes HH, Neale MC, Eaves LJ. Genetic and environmental factors in relative body weight and human adiposity. Behav Genet. 1997;27:325-51.

26. Ingalls AM, Dickie MM, Snell GD. Obese, a new mutation in the house mouse. J Hered. 1950;41:317-8.

27. Saunders CL, Chiodini BD, Sham P, et al. Meta-analysis of genome-wide linkage studies in BMI and obesity. Obesity (Silver Spring). 2007;15:2263-75.

28. Wang K, Li WD, Zhang CK, et al. A genome-wide association study on obesity and obesity-related traits. PLoS One. 2011;6: e18939.

29. Cheung CY, Tso AW, Cheung BM, et al. Obesity susceptibility genetic variants identified from recent genome-wide association studies: implications in a chinese population. J Clin Endocrinol Metab. 2010;95:1395-403.

30. Wang T, Huang Y, Xiao XH, et al. The association between common genetic variation in the FTO gene and metabolic syndrome in Han Chinese. Chin Med J (Engl). 2010;123:1852-8.

31. Wing MR, Ziegler JM, Langefeld CD, et al. Analysis of FTO gene variants with obesity and glucose homeostasis measures in the multiethnic Insulin Resistance Atherosclerosis Study cohort. Int J Obes (Lond). 2010.

32. Ng MC, Tam CH, So WY, et al. Implication of genetic variants near NEGR1, SEC16B, TMEM18, ETV5/DGKG, GNPDA2, LIN7C/BDNF, MTCH2, BCDIN3D/FAIM2, SH2B1, FTO, MC4R, and KCTD15 with obesity and type 2 diabetes in 7705 Chinese. J Clin Endocrinol Metab. 2010;95:2418-25.

33. Song Y, Altarejos J, Goodarzi MO, et al. CRTC3 links catecholamine signalling to energy balance. Nature. 2010;468:933-9.

34. Savoia C, Schiffrin EL. Inflammation in hypertension. Curr Opin Nephrol Hypertens. 2006;15:152-8.

35. Stehouwer CD, Gall MA, Twisk JW, et al. Increased urinary albumin excretion, endothelial dysfunction, and chronic low-grade inflammation in type 2 diabetes: progressive, interrelated, and independently associated with risk of death. Diabetes. 2002;51:1157-65.

36. Ross R. Atherosclerosis-an inflammatory disease. N Engl J Med. 1999;340:115-26.

37. Tracy RP. Emerging relationships of inflammation, cardiovascular disease and chronic diseases of aging. Int J Obes Relat Metab Disord. 2003;27 Suppl 3:S29-34.

38. Tracy RP. Inflammation, the metabolic syndrome and cardiovascular risk. Int J Clin Pract Suppl. 2003;134:10-17.

39. Karnoutsos K, Papastergiou P, Stefanidis S, et al. Periodontitis as a risk factor for cardiovascular disease: the role of antiphosphorylcholine and anti-cardiolipin antibodies. Hippokratia. 2008;12:144-9. 
40. Persson GR, Persson RE. Cardiovascular disease and periodontitis: an update on the associations and risk. J Clin Periodontol. 2008;35:362-79.

41. Watanabe K, Petro BJ, Shlimon AE, et al. Effect of periodontitis on insulin resistance and the onset of type 2 diabetes mellitus in Zucker diabetic fatty rats. J Periodontol. 2008;79:1208-16.

42. Nesbitt MJ, Reynolds MA, Shiau H, et al. Association of periodontitis and metabolic syndrome in the Baltimore Longitudinal Study of Aging. Aging Clin Exp Res. 2010;22:238-42.

43. Tsioufis C, Kasiakogias A, Thomopoulos C, et al. Periodontitis and blood pressure: the concept of dental hypertension. Atherosclerosis. 2011;219:1-9.

44. Page RC. The pathobiology of periodontal diseases may affect systemic diseases: inversion of a paradigm. Ann Periodontol. 1998;3:108-20.

45. Hung HC, Willett W, Merchant A, et al. Oral health and peripheral arterial disease. Circulation. 2003;107:1152-7.

46. Blake GJ, Rifai N, Buring JE, et al. Blood pressure, C-reactive protein, and risk of future cardiovascular events. Circulation. 2003;108:2993-9.

47. Blake GJ, Ridker PM. Novel clinical markers of vascular wall inflammation. Circ Res. 2001;89:763-71.

48. Sesso HD, Buring JE, Rifai N, et al. C-reactive protein and the risk of developing hypertension. JAMA. 2003;290:2945-51.

49. Savoia C, Schiffrin EL. Vascular inflammation in hypertension and diabetes: molecular mechanisms and therapeutic interventions. Clin Sci. 2007;112:375-84.

50. Griendling KK, Minieri CA, Ollerenshaw JD, et al. Angiotensin II stimulates NADH and NADPH oxidase activity in cultured vascular smooth muscle cells. Circ Res. 1994;74:1141-8.

51. Yamakawa T, Tanaka S, Numaguchi K, et al. Involvement of Rho-kinase in angiotensin II-induced hypertrophy of rat vascular smooth muscle cells. Hypertension. 2000;35:313-8.

52. Taubman MB, Berk BC, Izumo S, et al. Angiotensin II induces cfos mRNA in aortic smooth muscle. Role of $\mathrm{Ca} 2+$ mobilization and protein kinase C activation. J Biol Chem. 1989;264:526-30.

53. Ushio-Fukai M, Alexander RW, Akers M, et al. p38 Mitogenactivated protein kinase is a critical component of the redoxsensitive signaling pathways activated by angiotensin II. Role in vascular smooth muscle cell hypertrophy. J Biol Chem. 1998;273:15022-9.

54. Hernandez-Presa M, Bustos C, Ortego M, et al. Angiotensinconverting enzyme inhibition prevents arterial nuclear factorkappa B activation, monocyte chemoattractant protein-1 expression, and macrophage infiltration in a rabbit model of early accelerated atherosclerosis. Circulation. 1997;95:1532-41.

55. Schieffer B, Luchtefeld M, Braun S, et al. Role of $\mathrm{NAD}(\mathrm{P}) \mathrm{H}$ oxidase in angiotensin II-induced JAK/STAT signaling and cytokine induction. Circ Res. 2000;87:1195-201.

56. Jesmin J, Rashid MS, Jamil H, et al. Gene regulatory network reveals oxidative stress as the underlying molecular mechanism of type 2 diabetes and hypertension. BMC Med Genomics. 2010;3:45.

57. Tsuchida A, Yamauchi T, Takekawa S, et al. Peroxisome proliferator-activated receptor (PPAR)alpha activation increases adiponectin receptors and reduces obesity-related inflammation in adipose tissue: comparison of activation of PPARalpha, PPARgamma, and their combination. Diabetes. 2005;54:3358-70.

58. Chawla A, Barak Y, Nagy L, et al. PPAR-gamma dependent and independent effects on macrophage-gene expression in lipid metabolism and inflammation. Nat Med. 2001;7:48-52.

59. Shah P, Mittal A, Bharatam PV. CoMFA analysis of dual/multiple PPAR activators. Eur J Med Chem. 2008;43:2784-91.

60. Madhavan GR, Chakrabarti R, Reddy KA, et al. Dual PPARalpha and -gamma activators derived from novel benzoxazinone containing thiazolidinediones having antidiabetic and hypolipidemic potential. Bioorg Med Chem. 2006;14:584-91.
61. Koh KK, Quon MJ, Han SH, et al. Additive beneficial effects of losartan combined with simvastatin in the treatment of hypercholesterolemic, hypertensive patients. Circulation. 2004;110:368792.

62. Koh KK, Son JW, Ahn JY, et al. Simvastatin combined with ramipril treatment in hypercholesterolemic patients. Hypertension. 2004;44:180-5.

63. Esposito K, Pontillo A, Di Palo C, et al. Effect of weight loss and lifestyle changes on vascular inflammatory markers in obese women: a randomized trial. JAMA. 2003;289:1799-804.

64. Witkowska AM. Soluble ICAM-1: a marker of vascular inflammation and lifestyle. Cytokine. 2005;31:127-34.

65. - Sjogren P, Cederholm T, Heimburger M, et al. Simple advice on lifestyle habits and long-term changes in biomarkers of inflammation and vascular adhesion in healthy middle-aged men. Eur $\mathrm{J}$ Clin Nutr. 2010; 64: 1450-6. This article showed that even small efforts to improve diet and physical activity could influence biomarkers of inflammation. Such efforts may improve vascular function reducing the risk of diabetes and hypertension.

66. Yki-Järvinen H. Nonglycemic effects of insulin. Clin Cornerstone. 2003; Suppl 4: S6-12.

67. Jellinger PS. Metabolic consequences of hyperglycemia and insulin resistance. Clin Cornerstone. 2007;8 Suppl 7:S30-42.

68. Deedwania P. Hypertension, dyslipidemia, and insulin resistance in patients with diabetes mellitus or the cardiometabolic syndrome: benefits of vasodilating beta-blockers. J Clin Hypertens (Greenwich). 2011;13:52-9.

69. Stump CS, Clark SE, Sowers JR. Oxidative stress in insulinresistant conditions: cardiovascular implications. Treat Endocrinol. 2005;4:343-51.

70. Leiter LA, Lewanczuk RZ. Of the renin-angiotensin system and reactive oxygen species Type 2 diabetes and angiotensin II inhibition. Am J Hypertens. 2005;18:121-8.

71. Sharma AM, Engeli S. The role of renin-angiotensin system blockade in the management of hypertension associated with the cardiometabolic syndrome. J Cardiometab Syndr. 2006;1:29-35.

72. Ceriello A. Oxidative stress and glycemic regulation. Metabolism. 2000;49:27-9.

73. Boden G, Laakso M. Lipids and glucose in type 2 diabetes: what is the cause and effect? Diabetes Care. 2004;27:2253-9.

74. Avramoglu RK, Basciano H, Adeli K. Lipid and lipoprotein dysregulation in insulin resistant states. Clin Chim Acta. 2006;368:1-19.

75. Fonseca V, Desouza C, Asnani S, et al. Nontraditional risk factors for cardiovascular disease in diabetes. Endocr Rev. 2004;25:15375.

76. Meigs JB, Mittleman MA, Nathan DM, et al. Hyperinsulinemia, hyperglycemia, and impaired hemostasis: the Framingham Offspring Study. JAMA. 2000;283:221-8.

77. Grundy SM, Brewer Jr HB, Cleeman JI, et al. Definition of metabolic syndrome: Report of the National Heart, Lung, and Blood Institute/American Heart Association conference on scientific issues related to definition. Circulation. 2004;109:433-8.

78. Eckel RH, Grundy SM, Zimmet PZ. The metabolic syndrome. Lancet. 2005;365:1415-28.

79. Yeni-Komshian H, Carantoni M, Abbasi F, et al. Relationship between several surrogate estimates of insulin resistance and quantification of insulin-mediated glucose disposal in 490 healthy nondiabetic volunteers. Diabetes Care. 2000;23:171-5.

80. Lillioja S, Mott DM, Zawadzki JK, et al. In vivo insulin action is familial characteristic in nondiabetic Pima-Indians. Diabetes. 1987;36:1329-35.

81. Zoratti R, Godsland IF, Chaturvedi N, et al. Relation of plasma lipids to insulin resistance, nonesterified fatty acid levels, and body fat in men from three ethnic groups: relevance to 
variation in risk of diabetes and coronary disease. Metabolism. 2000;49:245-52.

82. Reaven GM. Relationships among insulin resistance, type 2 diabetes, essential hypertension, and cardiovascular disease: similarities and differences. J Clin Hypertens (Greenwich). 2011;13:238-43.

83. Morimoto K, Morikawa M, Kimura H, et al. Mental stress induces sustained elevation of blood pressure and lipid peroxidation in postmenopausal women. Life Sci. 2008;82:99-107.

84. Pickering TG. Mental stress as a causal factor in the development of hypertension and cardiovascular disease. Curr Hypertens Rep. 2001;3:249-54.

85. Esler M, Eikelis N, Schlaich M, et al. Chronic mental stress is a cause of essential hypertension: presence of biological markers of stress. Clin Exp Pharmacol Physiol. 2008;35:498-502.

86. Soucek M, Kara T. Stress-induced hypertension and diabetes mellitus. Vnitr Lek. 2001;47:315-9.

87. Seematter G, Guenat E, Schneiter P, et al. Effects of mental stress on insulin-mediated glucose metabolism and energy expenditure in lean and obese women. Am J Physiol Endocrinol Metab. 2000;279:E799-805.

88. Schnall PL, Pieper C, Schwartz JE, et al. The relationship between job strain, workplace diastolic blood-pressure, and leftventricular mass index - results of a case-control study. Jama-J Am Med Assoc. 1990;263:1929-35.

89. Jonas BS, Franks P, Ingram DD. Are symptoms of anxiety and depression risk factors for hypertension? Longitudinal evidence from the National Health and Nutrition Examination Survey I Epidemiologic Follow-up Study. Arch Fam Med. 1997;6:43-9.

90. Kario K, Ohashi T. After a major earthquake, stroke death occurs more frequently than coronary heart disease death in very old subjects. J Am Geriatr Soc. 1998;46:537-8.

91. Kario K, Ohashi T. Increased coronary heart disease mortality after the Hanshin-Awaji earthquake among the older community on Awaji Island. J Am Geriatr Soc. 1997;45:610-3.

92. Miller TQ, Smith TW, Turner CW, et al. A meta-analytic review of research on hostility and physical health. Psychol Bull. 1996;119:322-48.

93. Chapuis B, Vidal-Petiot E, Orea V, et al. Linear modelling analysis of baroreflex control of arterial pressure variability in rats. J Physiol. 2004;559:639-49.

94. Barrett CJ, Ramchandra R, Guild SJ, et al. What sets the longterm level of renal sympathetic nerve activity: a role for angiotensin II and baroreflexes? Circ Res. 2003;92:1330-6.

95. McDowall LM, Horiuchi J, Killinger S, et al. Modulation of the baroreceptor reflex by the dorsomedial hypothalamic nucleus and perifornical area. Am J Physiol Regul Integr Comp Physiol. 2006;290:R1020-1026

96. Julien C, Saul JP, Parati G. Very low frequency blood pressure fluctuations: not only myogenic responsiveness. J Hypertens. 2008;26:1065-8.

97. Kanbar R, Orea V, Chapuis B, et al. A transfer function method for the continuous assessment of baroreflex control of renal sympathetic nerve activity in rats. Am J Physiol Regul Integr Comp Physiol. 2007;293:R1938-1946.

98. Bachen EA, Muldoon MF, Matthews KA, et al. Effects of hemoconcentration and sympathetic activation on serum lipid responses to brief mental stress. Psychosom Med. 2002;64:58794.

99. Bjorntorp P. Visceral fat accumulation: the missing link between psychosocial factors and cardiovascular disease? J Intern Med. 1991;230:195-201.

100. Pickering T. Cardiovascular pathways: socioeconomic status and stress effects on hypertension and cardiovascular function. Ann N Y Acad Sci. 1999;896:262-77.

101. Narkiewicz K. Obesity-related hypertension: relevance of vascular responses to mental stress. J Hypertens. 2002;20:1277-8.

102. Bjorntorp P, Rosmond R. Neuroendocrine abnormalities in visceral obesity. Int J Obes Relat Metab Disord. 2000;24 Suppl 2: S80-85.

103. Pan XR, Li GW, Hu YH, et al. Effects of diet and exercise in preventing NIDDM in people with impaired glucose tolerance. The Da Qing IGT and Diabetes Study. Diabetes Care. 1997;20:537-44.

104. Eriksson KF, Lindgarde F. Prevention of type 2 (non-insulindependent) diabetes mellitus by diet and physical exercise. The 6-year Malmo feasibility study. Diabetologia. 1991;34:891-8.

105. Laaksonen DE, Lindstrom J, Lakka TA, et al. Physical activity in the prevention of type 2 diabetes: the Finnish diabetes prevention study. Diabetes. 2005;54:158-65.

106. Parker ED, Schmitz KH, Jacobs Jr DR, et al. Physical activity in young adults and incident hypertension over 15 years of followup: the CARDIA study. Am J Public Health. 2007;97:703-9.

107. Cederholm J, Wibell L. The relationship of blood pressure to blood glucose and physical leisure time activity. A study of hypertension in a survey of middle-aged subjects in Uppsala 1981-82. Acta Med Scand. 1986;219:37-46.

108. - Scott RA, Bailey ME, Moran CN, et al. FTO genotype and adiposity in children: physical activity levels influence the effect of the risk genotype in adolescent males. Eur J Hum Genet. 2010; 18: 1339-43. This article reported that in the GENESIS study, FTO genotype was only related to obesity in physically inactive males, highlighting physical activity as an important factor modifying the effect of FTO genotype.

109. Lee HJ, Kim IK, Kang JH, et al. Effects of common FTO gene variants associated with BMI on dietary intake and physical activity in Koreans. Clin Chim Acta. 2010;411:1716-22.

110. Sonestedt E, Gullberg B, Ericson U, et al. Association between fat intake, physical activity and mortality depending on genetic variation in FTO. Int J Obes (Lond). 2011;35:1041-1049.

111. Ruiz JR, Labayen I, Ortega FB, et al. Attenuation of the effect of the FTO rs9939609 polymorphism on total and central body fat by physical activity in adolescents: the HELENA study. Arch Pediatr Adolesc Med. 2010;164:328-33.

112. Fossum E, Gleim GW, Kjeldsen SE, et al. The effect of baseline physical activity on cardiovascular outcomes and new-onset diabetes in patients treated for hypertension and left ventricular hypertrophy: the LIFE study. Journal of Internal Medicine. 2007;262:439-48.

113. Mugo MN, Stump CS, Rao PG, et al. Hypertension and diabetes mellitus. In: Black HR, Elliott WJ, editors. Hypertension: A Companion to Braunwald's Heart Disease. Elsevier; 2007. p. 409.

114. Cheung BM. Drug treatment for obesity in the post-sibutramine era. Drug Saf. 2011;34:641-50. 